\title{
Northern Nigeria Maternal, Newborn and Child Health Programme: Selected Analyses from Population-Based Baseline Survey
}

\author{
Henry V. Doctor ${ }_{5}^{1, *}$, Radheshyam Bairagi ${ }^{2}$, Sally E. Findley ${ }^{3}$, Stephane Helleringer ${ }^{4}$ and Tukur \\ Dahiru \\ ${ }^{I}$ Columbia University, Mailman School of Public Health, Department of Population and Family Health, 60 Haven Ave- \\ nue - Suite B2, New York, NY 10032, USA \\ ${ }^{2}$ Independent researcher, India \\ ${ }^{3}$ Columbia University (same as ' 1 ' above) \\ ${ }^{4}$ Columbia University (same as '1' above) \\ ${ }^{5}$ Ahmadu Bello University, Department of Community Medicine, Zaria, Nigeria
}

\begin{abstract}
Maternal mortality in Northern Nigeria is among the highest in the world. To guide programme planning we interviewed 7,442 women in April and May 2009 in three northern states (Katsina, Yobe, and Zamfara) to understand patterns of antenatal care and delivery. Here, we present findings from a population-based survey conducted under the PRRINN-MNCH Programme to provide evidence-base programmatic interventions aimed at improving maternal and child health indicators. In the paper, we outline the health challenges facing northern Nigeria, describe the PRRINN$\mathrm{MNCH}$ Programme, describe the baseline survey design, implementation, and subsequent data. We provide a series of maternal and child health indicators in order to address two key important policy issues: (1) the importance of visits to health care facilities to enable women get proper maternal care, and (2) the importance of having access to skilled personnel at birth. We further describe how these data can be used to develop appropriate strategies for integrated programmes to increase awareness of pregnancy and delivery complications and to reduce the barriers to assessing risk and accessing the facilities in a timely manner. Appropriate strategies and interventions are necessary to address the existing health challenges. To a large extent, these data also provide an opportunity to measure the impact of the programme in assisting Nigeria attain the health Millennium Development Goals of maternal and child health.
\end{abstract}

Keywords: Antenatal care, fertility, immunization, maternal and child health, mortality, Nigeria.

\section{INTRODUCTION}

Maternal and child health (MCH) outcomes in Nigeria are among the worst in the world. Inadequate health facilities, lack of transportation to institutional care, inability to pay for services and resistance among some populations to modern health care are key factors behind the country's high rates of maternal, newborn and child mortality and morbidity $[1,2]$. The latest United Nations inter-agency estimates place the 2005 average national maternal mortality ratio (MMR) at 1,100 deaths per 100,000 live births, giving a lifetime risk of maternal death of 1 in 18 [2]. When these rates are viewed globally, the burden of maternal deaths is daunting: approximately 1 in every 9 maternal deaths occurs in Nigeria alone [2]. The situation in northern Nigeria is critical where strong cultural beliefs and practices on childbirth and fertility-related behaviors partly contribute significantly to the maternal morbidity and mortality picture [3] compared to southern Nigeria.

*Address correspondence to this author at Columbia University, Mailman School of Public Health, Department of Population and Family Health, 60 Haven Avenue - Suite B2, New York, NY 10032, USA;

E-mail: hvd2105@columbia.edu
Antenatal care (ANC) attendance is an important element of a comprehensive maternal health strategy [4, 5]. Utilization of ANC provides opportunities for a full range of health promoting services that may include weight and blood pressure measurement, screening and treatment for syphilis, prevention and presumptive treatment of malaria in pregnancy and health education, prevention of mother-to-child transmission of HIV, etc. Most importantly, ANC represents an opportunity to counsel women about possible serious complications to pregnancy and delivery and to promote institutional delivery. At each ANC visit, women can be asked whether they have experienced any of these complications and they can be reminded what to do if any occur.

The importance of skilled attendance at delivery has long been recognized [e.g., 6, 7], and ANC visits also serve to encourage women to have skilled attendants at birth at a facility, who can provide life-saving emergency obstetric care interventions to women who develop serious complications. However, distance to health facilities, inadequate transportation, socio-cultural beliefs and the need for immediate and specialized services have hampered women's ability to access these services in many low- and middle-income countries, including Nigeria [see 3, 8, 9]. Attention to clean and 
hygienic delivery practices [10] and the provision of essential care for the newborn, such as thermal protection and early and exclusive breast-feeding [11], are important interventions which can improve health outcomes of all infants, whether born at home or in a health care facility. Community and primary care level interventions aimed at increasing these critical elements of ANC have been found to be highly cost-effective.

In the context of a Maternal, Newborn and Child Health $(\mathrm{MNCH})$ Programme targeting three states in northern Nigeria (Katsina, Yobe and Zamfara) funded by the Norwegian Government and implemented by the UK Department for International Development (DfID), a quantitative baseline study was conducted to develop an evidence base to support the selection of appropriate programme strategies to reduce the unacceptably high rates of maternal, newborn and child mortality. In order to measure service coverage and prevailing knowledge, attitudes, behaviours and practices in the programme intervention areas, population-based data were collected. Baseline data were also needed to assess the impact of the programme on improving health outcomes and survival rates, and thereby contributing to achievement of the national health Millennium Development Goals (MDGs). Repeating the survey periodically will enable an assessment of the contribution of the interventions and systemic changes on health systems strengthening and improvement of health outcomes.

Recognizing the unacceptably high maternal, newborn and child mortality rates in northern Nigeria and the virtually dysfunctional primary health care (PHC) services, the $\mathrm{MNCH}$ Programme aims at providing innovations to provide essential care for women, babies and children. These innovations are aimed at providing an enduring capacity to improve health outcomes and survival rates and being well positioned to make substantive progress towards the health MDGs. The $\mathrm{MNCH}$ Programme also provides an opportunity for advancing the study of organisations and social institutions in developing countries that may be shaping critical health and demographic behaviors and outcomes. Therefore, this paper describes the background, methods, and selected results from the MNCH Baseline Survey (MNCH-BS) 2009. Although we present selected $\mathrm{MCH}$ indicators, the focus of this paper is to address two key policy issues: (1) the importance of visits to health care facilities to enable women get proper maternal care, and (2) the importance of having access to skilled personnel at birth. We address these issues by attempting to answer the following summary question: are women who utilize health care facilities during ANC more likely to have skilled personnel at birth? Answering this question is very important since ANC attendance is, ceteris paribus, a summary measure of a woman's ability or empowerment to take proper care of herself and the unborn baby.

\section{PROGRAMME SETTING}

With approximately 140 million people based on the 2006 Population and Housing Census, Nigeria's population is unevenly distributed across the country. The average population density in 2006 was estimated at 150 people per square kilometer with Lagos, Anambra, Imo, Abia, and Akwa Ibom being the most densely populated states. Most of the densely populated states are found in the South East. Kano state, with an average density of 442 persons per square kilometre, is the most densely populated state in the north [12].

A national health policy targeted at achieving health for all Nigerians was disseminated in 1988 and revised in 2004 in response to emerging issues and the need to focus on realities and trends. The revised policy describes the goals, structure, strategy, and policy direction of Nigeria's health care delivery system [13]. The policy's ultimate goal is to provide adequate access to primary, secondary, and tertiary health care services through a functional referral system. The overall objective of the revised policy is to reinforce the national health system thereby leading to provision of effective, efficient, quality, accessible and affordable health services that will improve the health status of Nigerians. This achievement will be assessed through progress towards attainment of the health related MDGs [12].

The national health policy considers PHC as critical in achieving improved health for the population. PHC services include health education; adequate nutrition; safe water and sanitation; reproductive health, including family planning; immunisation against five major infectious diseases; the provision of essential drugs; and disease control. The policy document requires that a comprehensive health care system delivered through the primary health centers should include $\mathrm{MCH}$ care, including family planning services.

Regional disparities exist in health service delivery and resource availability [14]. The southern states enjoy more health services than the northern states. This disparity is reflected in a number of health outcomes. For example, the 2008 Nigeria Demographic and Health Survey (DHS) reports a child mortality rate ranging from a low of 32 deaths per 1,000 children in the South West zone to 139 deaths per 1,000 children in the North West zone. In order to improve, inter alia, child survival, the current priorities in the health sector focus on childhood immunisation, malaria and diarrhea prevention and treatment, and HIV/AIDS prevention [12].

\section{THE MNCH PROGRAMME IN NORTHERN NIGE- RIA}

Briefly, the four-year MNCH Programme aims at improving the quality and availability of all maternal, newborn and child health services in Katsina, Yobe, and Zamfara States. These services include antenatal and postnatal care; safer deliveries; care for newborn and young children; improved nutrition; routine immunisation; and effective PHC. The MNCH and the existing Partnership for Reviving Routine Immunisation in Northern Nigeria (PRRINN) programmes are closely linked and a number of their outputs and activities are inter-dependent. The two programmes are viewed as a single entity by in-country stakeholders.

The health systems-strengthening objectives of the MNCH Programme enables PRRINN goals and objectives to be achieved more effectively and will help to ensure that achievements can be sustained in the medium- to long-term. Health Partners International, Save the Children and GRID Consulting of Nigeria are managing the $\mathrm{MNCH}$ Programme 
with assistance from the Mailman School of Public Health at Columbia University, Ahmadu Bello University, Liverpool Associates in Tropical Health and Health Reform Foundation of Nigeria.

\section{THE MNCH 2009 BASELINE SURVEY DESIGN}

The MNCH-BS 2009 was conducted in April and May 2009 in Katsina, Yobe and Zamfara States. The 2006 population census results show that Katsina (in the North West) has a population of 5.8 million whereas Yobe (North East) and Zamfara (North West) have 2.3 million and 3.3 million people respectively. For the survey, consent was sought from all individuals to be interviewed. The purpose of the study and what the results would be used for was explained. Respondents were told that they had a free choice about whether or not to participate. Refusals account for $0.9 \%$ $(n=69)$ of all eligible respondents.

In each state, the $\mathrm{MNCH}$ Programme is implemented through an approach that phases capacity building and health system strengthening activities in clusters of Local Government Areas (LGAs). The sample design therefore needed to include enough respondents in these clusters to allow estimation of programme impact. For this reason, we used a stratified two-stage cluster, random sample survey. The sample was designed to be representative of all women of reproductive age (15-49 years) in the three states. Each of the states was divided into two strata: LGAs with intensive $\mathrm{MNCH}$ activities (i.e., core clusters) and the LGAs with less intensive MNCH activities (i.e., 'other' clusters). The core clusters were oversampled to facilitate impact evaluation in the future. An Enumeration Area (EA) within a stratum was the first stage; with this first-stage EA selected using probability proportional to size. From the core cluster and 'other' clusters, 30 EAs and 15 EAs were selected respectively. For the second stage or selection process, in each of the selected EAs, 47 households were selected at random for interviews. Thus, the household was the ultimate sampling unit. Within each randomly selected household, all married and evermarried women of reproductive age were eligible for interview $(\mathrm{n}=7,442)$.

Since the number of EAs in the two strata was different and the population size in each of the clusters may be different, the probability of selection of a household/woman between clusters within a state was different. As a result, analysis of the survey data used sampling weights to correct for the oversampling in the core clusters and make the data statistically representative. The sampling weights enabled detailed characteristics pertaining to the population and $\mathrm{MNCH}$ health status indicators and behaviors for each state, as well as comparisons between states and analysis of the situation of all three states together.

In the survey, a household was defined as a family with one head of household, eating and sleeping under the same roof. Families were defined as all those who live and eat together, including non-relatives, such as domestic servants or fostered children. From compounds with one to three households, one household was randomly chosen for interviews; from compounds with four to six households, two were surveyed; from compounds with seven or more households, three were surveyed. Regardless of the number of households selected for interview within a compound, all eligible women within the selected households were interviewed. Criteria for eligibility of individual respondents included having ever been married and being aged 15-49 years at the time of the survey. Trained interviewers visited the selected women at home and administered a questionnaire which included translation of key concepts and terms in the local languages (e.g., Hausa, Kanuri).

\section{SELECTED RESULTS}

We present the results beginning with a description of the respondent characteristics followed by a discussion of fertility measures, MCH (our key policy issues) indicators, vaccination of children, health seeking behaviour, and infant and child mortality indicators.

\section{Respondent Characteristics}

The overall individual response rate was $91.5 \%$ with the highest response rate observed in Yobe at $96.7 \%$ followed by Zamfara at $91.3 \%$ and Katsina at $89.6 \%(\mathrm{p}<0.001)$. Table $\mathbf{1}$ provides an overview of the respondent's characteristics. The mean age at last birthday of all women was 28.7 years with $97.2 \%$ of all women being currently married at the time of the survey. The mean children ever born (CEB) was 4.3 for all women with the lowest in Yobe (3.8) compared with Katsina (4.6) and Zamfara (4.2). Women with formal schooling accounted for $18.8 \%$ with the highest in Katsina (28.9\%) followed by Yobe (13.2\%) and Zamfara $(6.7 \%)$. Of all women with formal schooling, 53\% attained primary schooling. Although Hausa is widely spoken in northern Nigeria, the results show that $78.1 \%$ of women are unable to read and write in Hausa. Overall, the Hausa people are a majority at $72.6 \%$ followed by the Fulani, Kanuri, and 'other' ethnic groups at $16 \%, 6.2 \%$ and $5.2 \%$ respectively. With $7.9 \%$ of all women owning a mobile phone, state specific differences show that Yobe State had the highest rate of mobile phone ownership (11.0\%) compared with Katsina (8.4\%) and Zamfara $(4.8 \%)$. The highest proportion of women living in hardto-reach areas (i.e., with difficult terrain) was observed in Zamfara at $55.1 \%$ followed by Yobe at $49.2 \%$ and Katsina at $37.0 \%(\mathrm{p}<0.001)$.

\section{Fertility}

The fertility measures are based on the pregnancy histories collected during interviews with married and evermarried women aged 15-49 years. Each woman was asked a series of questions that could be used to construct a retrospective history of all her pregnancies and births. To encourage complete reporting, the interviewer asked the respondent about the number of sons and daughters living with her, the number living elsewhere, and the number who had died. She was then asked for a history of all of her pregnancies including the year of birth, name, sex, and survival status of each birth. For pregnancies in the previous five years, the woman was asked to provide details about ANC, knowledge of pregnancy and delivery complications, place and type of delivery, and care for the newborn.

Selected measures of current fertility are calculated for the 5-year period preceding the survey-roughly corresponding to the calendar years 2005-2009. A 5-year period was chosen because it reflects the current situation without un- 
Table 1. Descriptive Overview of Respondent Characteristics, MNCH-BS 2009

\begin{tabular}{|c|c|c|c|c|}
\hline Characteristics & Katsina & Yobe & Zamfara & All States \\
\hline Mean age at last birth day & 28.8 & 27.9 & 29.0 & 28.7 \\
\hline Currently married & 96.5 & 97.3 & 98.2 & 97.2 \\
\hline Mean children ever born & 4.6 & 3.8 & 4.2 & 4.3 \\
\hline Has formal schooling & 28.9 & 13.2 & 6.7 & 18.8 \\
\hline Has primary schooling & 57.3 & 41.8 & 44.1 & 53.0 \\
\hline Unable to read and write in Hausa & 70.9 & 86.5 & 83.5 & 78.1 \\
\hline \multicolumn{5}{|l|}{ Ethnicity } \\
\hline Hausa & 83.5 & 24.3 & 87.9 & 72.6 \\
\hline Kanuri & 2.0 & 24.7 & 0.4 & 6.2 \\
\hline Fulani & 13.3 & 29.9 & 10.9 & 16.0 \\
\hline Other & 1.3 & 21.1 & 0.8 & 5.2 \\
\hline Has a mobile phone & 8.4 & 11.0 & 4.8 & 7.9 \\
\hline Lives in hard-to-reach areas & 37.0 & 49.2 & 55.1 & 44.8 \\
\hline $\mathbf{N}$ (completed interviews) & 3,373 & 1,419 & 2,033 & 6,825 \\
\hline
\end{tabular}

Notes: All differences are significant ( $\mathrm{p}<0.001)$ except for 'currently married' ( $\mathrm{p}<0.05)$; Unless otherwise stated, all numbers in columns are reported in percent.

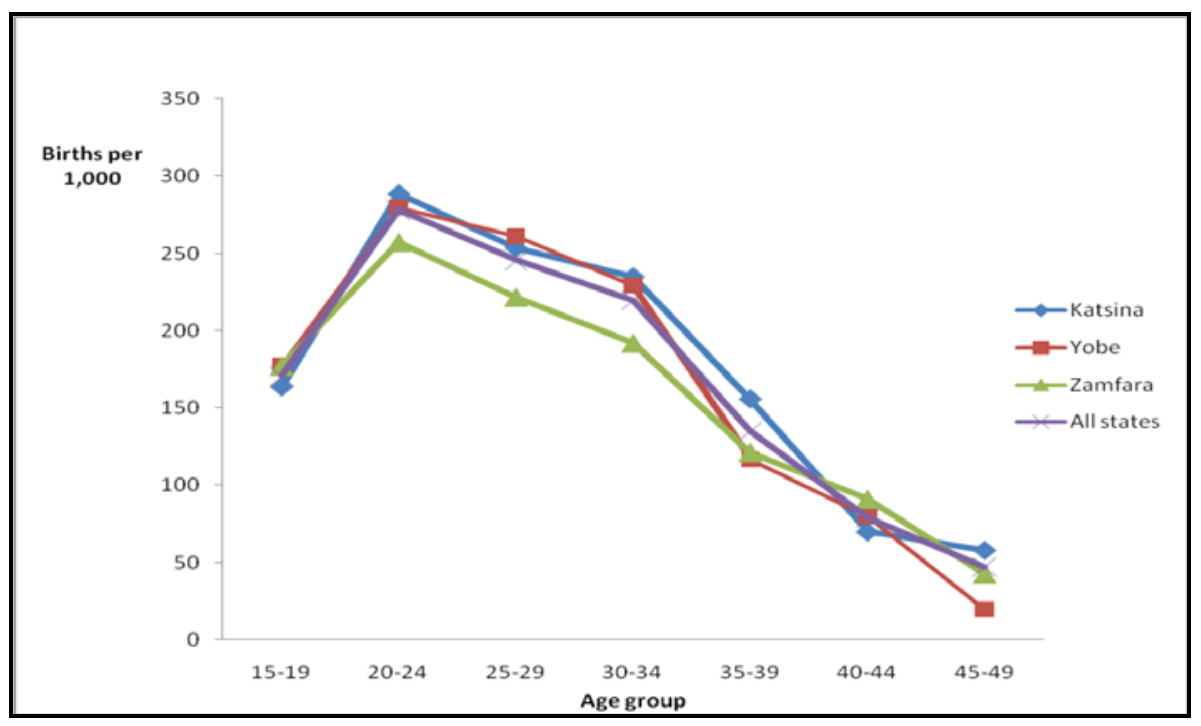

Fig. (1). Age specific fertility rates by state (MNCH-BS, 2009).

duly increasing sampling error, while allowing the birth rates to correspond to the same reference period as the information regarding ANC, delivery, and immunisations, which was collected only for children born during the last five years. Using a 5-year reference period increases the chance of recall errors, particularly for older women whose births may have been earlier in the 5-year recall period. Thus, the age specific fertility rate (ASFR) could be underestimated at older ages, compared to when the rates are calculated from a 1-year or 3-year reference period, as in the DHS.

Despite efforts to improve data quality, baseline survey data are subject to the same types of errors that are inherent in all retrospective sample surveys, including: poor recall of events surrounding pregnancies and births occurring more than 3 years before the survey; the possibility of omitting some births (especially births of children who died at a very young age) and the difficulty of accurately determining each child's date of birth due to high illiteracy levels. These errors may be more pronounced among the illiterate as is the case with majority of women in our sample. Rates may also be low due to the exclusion of any births to the never-married women or to those younger than age 15 or older than age 49 . These errors can bias estimates of fertility levels and trends, which therefore have to be interpreted within the context of data quality and sample sizes.

The ASFRs by state are displayed in Fig. (1) which show that all women exhibit a pattern of childbearing for quite a long period of their reproductive life from early years with a peak within the 20-24 age group. This is fairly typical of societies with high fertility. 
Table 2. Total Fertility Rate and Children Ever Born by Age 40-49, MNCH-BS 2009

\begin{tabular}{|c|c|c|}
\hline Characteristics & TFR & CEB ( 40-49) \\
\hline \hline Residence & & 7.3 \\
\hline Rural & 6.7 & 7.5 \\
\hline Urban & 4.6 & 7.9 \\
\hline State & & 6.7 \\
\hline Katsina & 6.6 & 6.9 \\
\hline Yobe & 5.8 & \\
\hline Zamfara & 5.5 & 7.2 \\
\hline Education level & & 7.2 \\
\hline None & 6.7 & 6.9 \\
\hline Primary & 6.6 & $\mathbf{7 . 4}$ \\
\hline Secondary or higher & 5.2 & \\
\hline Total & $\mathbf{5 . 9}$ & \\
\hline
\end{tabular}

\section{Fertility Differentials and Trends}

Table 2 shows differentials in fertility by residence (urban-rural), state and education level. In the three states, the urban total fertility rate (TFR) of 4.6 is considerably lower than the 6.4 for rural areas, and these results closely match with the national urban and rural TFR from the 2008 Nigeria DHS (4.7 and 6.3 respectively). In all the states, the rural TFR of 6.7 exceeds the urban TFR of 4.6 by 2.1 children possibly indicating that the urban-rural fertility differential reflects differences in marital rates, namely later age at marriage among urban women.

Fertility also varies by state. Katsina's TFR is higher (6.6) than Yobe (5.8) and Zamfara (5.5). As is often the case, fertility rates are lower among women with higher levels of formal education. Although the TFR for women with no education and primary education differs little (6.7 versus 6.6 ), it decreases to 5.2 children for women with secondary and higher education.

Comparison of the mean number of CEB for women aged 40-49 $\left(\mathrm{CEB}_{40-49}\right)$ with the TFR allows for a comparison of current and previous fertility. As a measure of past or completed fertility, the $\mathrm{CEB}_{40-49}$ is subject to possible underreporting of births, particularly of children who have subsequently died and reflects earlier fertility patterns that were in effect when the current 40-49 year olds were beginning their marriages and families. If TFR and $\mathrm{CEB}_{40-49}$ were approximately the same, this would provide evidence that fertility rates had changed little in the past 20 or so years. If $\mathrm{CEB}_{40-49}$ is greater than the TFR, then current fertility would have declined from higher levels in the past. As shown in Table $\mathbf{2}$, the CEB $40-49$ is consistently higher than the TFR. Compared to women beginning their reproductive periods today, women who began their reproductive lives 20 years ago had 1.5 more children than today's young women can expect to have. The greatest recent declines in fertility appear to have occurred in urban areas and among women with secondary or higher education, and to have been relatively greater in Katsina and Zamfara states.

\section{Maternal and Child Health}

The MNCH-BS 2009 also collected information on health services use during and after pregnancy, ANC, characteristics of the newborn, and knowledge of pregnancy complications. This information can be used to identify women who may be at risk because of non use of health services and provide a basis for implementing appropriate interventions. The results presented in the following sections are based on data on all live births that occurred in the five years preceding the survey.

Analysis of $\mathrm{MCH}$ indicators provides an opportunity to assess the extent to which women visit health care facilities to enable them get proper maternal care and the possibility of ensuring that they understand the need for having access to skilled personnel at birth. Results show that only $24.9 \%$ of women who gave birth in the five years preceding the survey ever received ANC from a trained health professionals (i.e., a doctor, nurse/midwife). ${ }^{1}$ The highest percentage of women receiving ANC coverage was observed in Katsina (32.0\%) followed by Yobe $(25.5 \%)$ and Zamfara $(10.5 \%)(\mathrm{p}=0.005)$. For all live births in the past five years, only $11.2 \%$ reported that their births were delivered by a health professional. An even lower proportion, $9.4 \%$, delivered in a health facility.

Most women receiving ANC began their visits during the second trimester. Although seeking advice on health is an important element in ensuring improved $\mathrm{MCH}$, results show that $75.1 \%$ of women never did so. About $3 \%$ of women sought advice from their friends, with a similar proportion seeking advice from co-wives.

Knowledge of complications during pregnancy can reduce the risk of death. The results show that more women in Yobe $(12.7 \%)$ did not know any complications compared with women in Zamfara (6.8\%) and Katsina (1.3\%) $(\mathrm{p}<0.001) .{ }^{2}$ Home deliveries are nearly universal $(87.2 \%$ of 
Table 3. Logistic Regression of Skilled Assistance at Delivery on ANC Attendance During Most Recent Pregnancy Five Years Before the MNCH-BS 2009

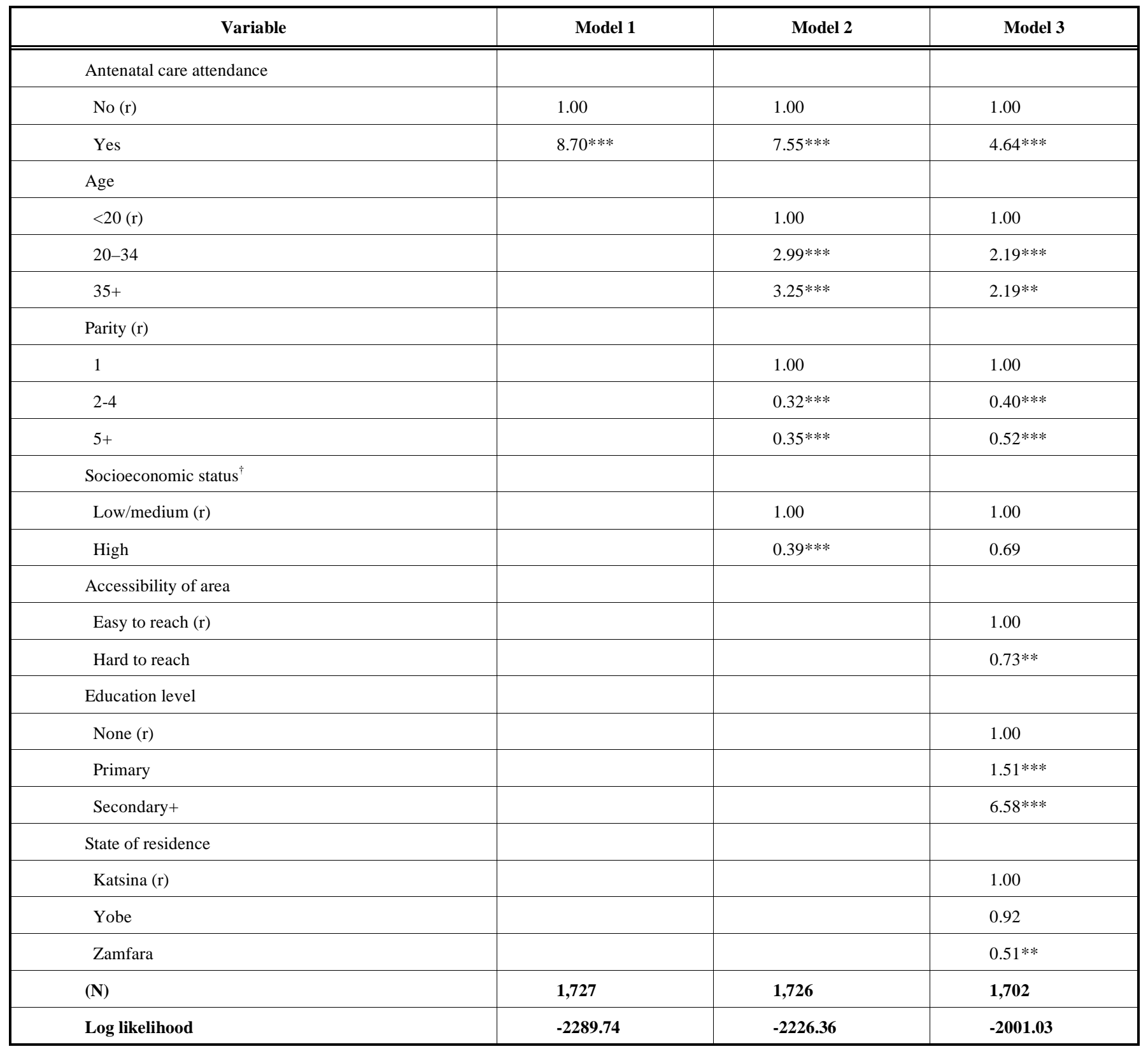

Note: $(\mathrm{r})=$ Reference category; ${ }^{* * *}$ Significant at $\mathrm{p} \leq 0.001 ;{ }^{* *} \mathrm{p} \leq 0.05{ }^{\dagger}$ Based on household assets (e.g., radio ownership, animal possessions).

all women reporting home delivery). About $95 \%$ of women in Zamfara reported home deliveries, compared with $87.2 \%$ and $82.3 \%$ in Yobe and Katsina respectively $(\mathrm{p}<0.001){ }^{3}$ Corresponding figures from the Nigeria 2008 DHS are $92.3 \%, 92.9 \%$, and $93.1 \%$ respectively. For women who deliver at home, the most common reason cited was that it is more comfortable to deliver at home than at a facility $(43.8 \%)$.

We address the policy issues related to the importance of visits to health care facilities and having access to skilled personnel at birth by using multivariate logistic regression to assess the independent influence of ANC attendance on the decision to deliver at a health facility during the most recent pregnancy. The dependent variable takes on the value " 0 " if the woman delivered outside a health facility and " 1 " if she delivered at a facility. Similarly, the independent variable is coded as " 0 " for those who did not attend ANC and " 1 " for those who attended ANC. These analyses (see Table 3) which are reported in form of odds ratios (ORs) controlled for age, parity, socio-economic status (SES), accessibility of respondent's community, education level, and state of residence. Model 1 tests the baseline effect of ANC attendance on place of delivery whereas Model 2 controls the effect of mother's age, parity, and socio-economic status. Model 3 controls for accessibility of respondent's community, education level, and state of residence.

ANC attendance and other socio-demographic factors were significant predictors of having a birth at a facility. In 
Table 4. Specific Vaccines Reported As Given At Any time Before the Survey and Vaccination Card Seen by Background Characteristics, Children 12-23 Months of Age (Percent)

\begin{tabular}{|c|c|c|c|c|c|c|c|}
\hline Characteristics & BCG & DPT3 & Polio3 & Measles & $\begin{array}{c}\text { All Recommended } \\
\text { Doses }\end{array}$ & Card Seen & $\begin{array}{c}\text { Number of } \\
\text { Children }\end{array}$ \\
\hline \multicolumn{8}{|l|}{ State } \\
\hline Katsina & 33.4 & 5.7 & 28.0 & 21.4 & 2.5 & 17.5 & 988 \\
\hline Yobe & 26.9 & 9.2 & 22.9 & 24.4 & 3.8 & 16.8 & 433 \\
\hline Zamfara & 15.8 & 0.8 & 23.6 & 14.8 & 0.2 & 9.1 & 560 \\
\hline \multicolumn{8}{|l|}{ Settlement } \\
\hline Urban & 37.5 & 7.1 & 28.5 & 26.3 & 4.6 & 19.3 & 599 \\
\hline Rural & 22.5 & 4.2 & 24.5 & 17.5 & 1.1 & 13.1 & 1,382 \\
\hline All 3 states & 27.0 & 5.1 & 25.7 & 20.1 & 2.2 & 15.0 & 1,974 \\
\hline
\end{tabular}

Model 1, we find that women who attend ANC had an OR of 8.70 compared with women who did not attend ANC. In Model 2, the impact on ANC attendance on facility delivery was similar to Model 1 although the OR reduces by about 1.2 points. We also find that compared with young mothers (<20 years), older mothers are about three times more likely to deliver at a health facility. High parity women are about $65-68 \%$ less likely to have a facility delivery than women at parity 1 . Women belonging to high SES households are $61 \%$ less likely to deliver at a health facility. The effect of SES on delivery at a facility may be related to the fact that most women come from poor households and that the 'rich-poor' gap based on household possessions is virtually insignificant. Although the introduction of accessibility, education level and state of residence in Model 3 reduces the effect of ANC attendance on having a facility delivery, the OR is still high (4.64) and robust. Further, the effect of the other variables (when compared to Model 2) is similar. The key results in Model 3 are that women from hard-to-reach areas are $27 \%$ less likely to have a facility delivery than those from easy-toreach areas. In addition, having primary and secondary schooling is associated with higher odds of delivering at a facility (ORs $=1.51$ and 6.58 respectively). Women in the relatively poor Zamfara state are $49 \%$ less likely to deliver at a facility than those from Katsina state.

\section{Vaccination of Children}

According to the Nigerian Federal Ministry of Health definition, a child is considered fully vaccinated if he or she has received a BCG vaccination against tuberculosis; three doses of DPT to prevent diptheria, pertussis (whooping cough), and tetanus; at least three doses of polio vaccine; and one dose of measles vaccine. All these vaccinations should be received during the first year of life, over the course of five visits, including the doses delivered at birth. According to this schedule, children aged 12-23 months would have completed their immunisations and be fully immunised. To keep track of the delivery of these immunisations, Nigeria also provides parents or guardians with a health card on which each dose is to be recorded.

We report only immunisations completed for children aged 12-23 months, the usual age group for reporting immu- nisation rates, and hence these rates are comparable to the Nigerian DHS and international immunisation surveys. Table 4 shows that one-fourth of all children aged 12-23 months had received the three recommended doses of polio, but many missed the corresponding third dose of DPT3, which was received by only $5.1 \%$ of one-year olds. Only $2.2 \%$ of children $12-23$ months of age received all recommended doses. More children in Yobe (3.8\%) than in Katsina $(2.5 \%)$ and Zamfara $(0.2 \%)$ had received all recommended doses $(p=0.05)$. Further analysis of the data shows that $67 \%$ of parents were unable to receive all immunisations reported lack of vaccine as a problem, and 13\% had difficulties with the long wait.

Children in the urban areas have consistently higher immunisation rates than those in the rural areas. Overall, $4.6 \%$ of children 12-23 months of age had received all of the recommended doses by one year, compared to $1.1 \%$ in the rural areas $(p=0.005)$. The greatest urban advantage is associated with the BCG dose, which is administered at birth and probably reflects the higher proportion of births in health care facilities in the urban areas. For DPT3 and Polio3 the urban and rural rates are much closer.

\section{Health Seeking Behaviour}

Fever, cough and dehydration from diarrhoea are important contributing causes of childhood morbidity and mortality in less developed countries. Timely medical attention during episodes of these illnesses is crucial in reducing child deaths. In the MNCH-BS 2009, information pertaining to experience of an episode of fever, cough and diarrhoea was collected for up to four children under 5 years of age. Mothers were asked to provide information related to these illnesses in the two weeks preceding the survey. Information was also collected on the percentage of episodes in which mothers sought treatment for their children. The morbidity data collected are based only the mother's perception of illnesses, without validation by medical personnel.

The results briefly show that treatment from a health facility or provider was sought for $30.7 \%$ of the children with symptoms of fever/cough. For children with diarrhoea, $37.9 \%$ were taken to a health facility or health provider for treatment. Treatment for diarrhoea resulted in use of oral 
Table 5. Early Childhood Mortality Rates by State (During 2005-2009) for the Five-Year Period Preceding the MNCH-BS 2009

\begin{tabular}{|c|c|c|c|c|c|}
\hline State & $\begin{array}{c}\text { Neonatal Mortality } \\
\text { Rate (NNMR) }\end{array}$ & $\begin{array}{c}\text { Post-Neonatal Mor- } \\
\text { tality Rate (PNNMR) }\end{array}$ & $\begin{array}{c}\text { Infant Mortality Rate } \\
\text { (IMR) }\end{array}$ & $\begin{array}{c}\text { Child Mortality Rate } \\
\text { (CMR 1-4) }\end{array}$ & $\begin{array}{c}\text { Under-Five Mortality } \\
\text { Rate (U5MR) }\end{array}$ \\
\hline \hline Katsina & 30 & 60 & 90 & 99 & 180 \\
\hline Yobe & 20 & 40 & 60 & 64 & 120 \\
\hline Zamfara & 30 & 70 & $\mathbf{6 0}$ & $\mathbf{9 0}$ & $\mathbf{7 7}$ \\
\hline All 3 states & $\mathbf{3 0}$ & $\mathbf{6 0}$ & $\mathbf{7 5}$ & $\mathbf{8 8}$ & $\mathbf{1 6 0}$ \\
\hline DHS 2008 (2004-2008) & $\mathbf{4 0}$ & $\mathbf{3 5}$ & $\mathbf{1 5 7}$ \\
\hline
\end{tabular}

Note: "National level figures.

rehydration salts (ORS) for $32.7 \%$ of all illness episodes and salt sugar solution for $15.9 \%$. A quarter of the children with diarrhoea were given some sort of oral rehydration therapy which includes solution prepared from packets of ORS, prepackaged ORS liquids, and recommended home fluids. Just over a quarter $(27 \%)$ of mothers continued with breastfeeding during episodes of diarrhoea.

\section{Infant and Child Mortality}

It is widely acknowledged that infant and child mortality rates reflect a country's level of socioeconomic development and quality of life [15]. These mortality rates are used for monitoring and evaluating population and health programmes and policies. The following sub-sections provide information on mortality of children under age five. Specifically, they present information on levels and differentials in neonatal, post-neonatal, infant and child mortality. Mortality estimates are disaggregated by socioeconomic characteristics such as urban-rural residence, mother's education and by selected demographic characteristics in order to identify segments of the population requiring special attention.

\section{Levels and Trends in Infant and Child Mortality}

Mortality rates for children under five years of age for the 5-year period preceding the survey are presented in Table 5. Results show that under-five mortality rate (U5MR) was 160 per 1,000 live births. That is, 1 in about 6 children born dies before reaching the fifth birthday. The infant mortality rate (IMR) was 90 deaths per 1,000 live births and the child mortality rate (CMR) was 77 deaths per 1,000 children. Katsina had the highest CMR (99) followed by Yobe at 64 and Zamfara at 66 deaths per 1,000 children. Post-neonatal mortality rate (PNNMR) during the five years preceding the survey was 60 deaths per 1,000 live births with Zamfara taking a lead at 70 deaths per 1,000 live births followed by Katsina and Yobe at 60 and 40 deaths per 1,000 live births respectively. Neonatal mortality rate (NNMR) was estimated at 30 deaths per 1,000 live births with the highest observed in Zamfara and Katsina at 30 deaths per 1,000 live births and the lowest in Yobe at 20 deaths per 1,000 live births. ${ }^{4}$

\section{Socio-economic Differentials in Infant and Child Mortal- ity}

Table 6 provides information on the socio-economic differentials in infant and child mortality. Results show that male children had higher NNMRs than female children. This pattern of gender differentials in neonatal mortality is the norm, because NNMRs (which reflects largely congenital conditions) tend to be higher for boys than girls. In contrast, rates that do not include the first month of life, such as PNNMRs, are similar for male and female children. By the time child mortality is considered, females tend to be disadvantaged than males. When child mortality is higher for females than for males, this corresponds to a social and cultural pattern of son preference, as has been observed particularly in South and East Asia. Son preference is often associated with nutritional and medical benefits being directed more towards male than female children, with resultant malnutrition and heightened mortality risk for female children [16-17]. The results of this survey suggest the possibility of a son preference in northern Nigeria.

Child mortality at all ages tends to be highest among children born to women in the oldest age group, a typical pattern found throughout the world. Also, as is the case elsewhere, infant and under-five mortality are relatively high in the youngest age group. Partially related to this age pattern, childhood mortality rates also tend to have a U-shaped relationship with birth order, with first births and higher order births having elevated mortality rates. Birth order shows the expected U-shaped pattern for neonatal, infant and U5MRs, with rates being higher for first births and births of order seven or higher compared with second to sixth-order births. In contrast, child mortality tends to increase linearly with birth order. The increase in the CMR with birth order may reflect a more intense competition faced by higher birth order children for the caregiver's time, utilisation of health care, and for nutritious food once children are weaned. In addition, this may be affected by the mother's age since child birth in the old age is a physiological burden for women that may have an impact on the health of the children.

ANC visits have clear beneficial effect on reducing infant and under-five mortality. The same is also true in the case of place of delivery. Delivery at a health care facility is associated with subsequent reductions in neonatal, infant and under-five mortality.

\section{SUMMARY}

We began this paper by outlining the health challenges facing northern Nigeria, described the PRRINN-MNCH Programme, the baseline survey design, implementation, and subsequent data. We provided a series of demographic and 
Table 6. Early Childhood Mortality Rates by Demographic and ANC Use for the Five-Year Period Preceding the MNCH-BS 2009

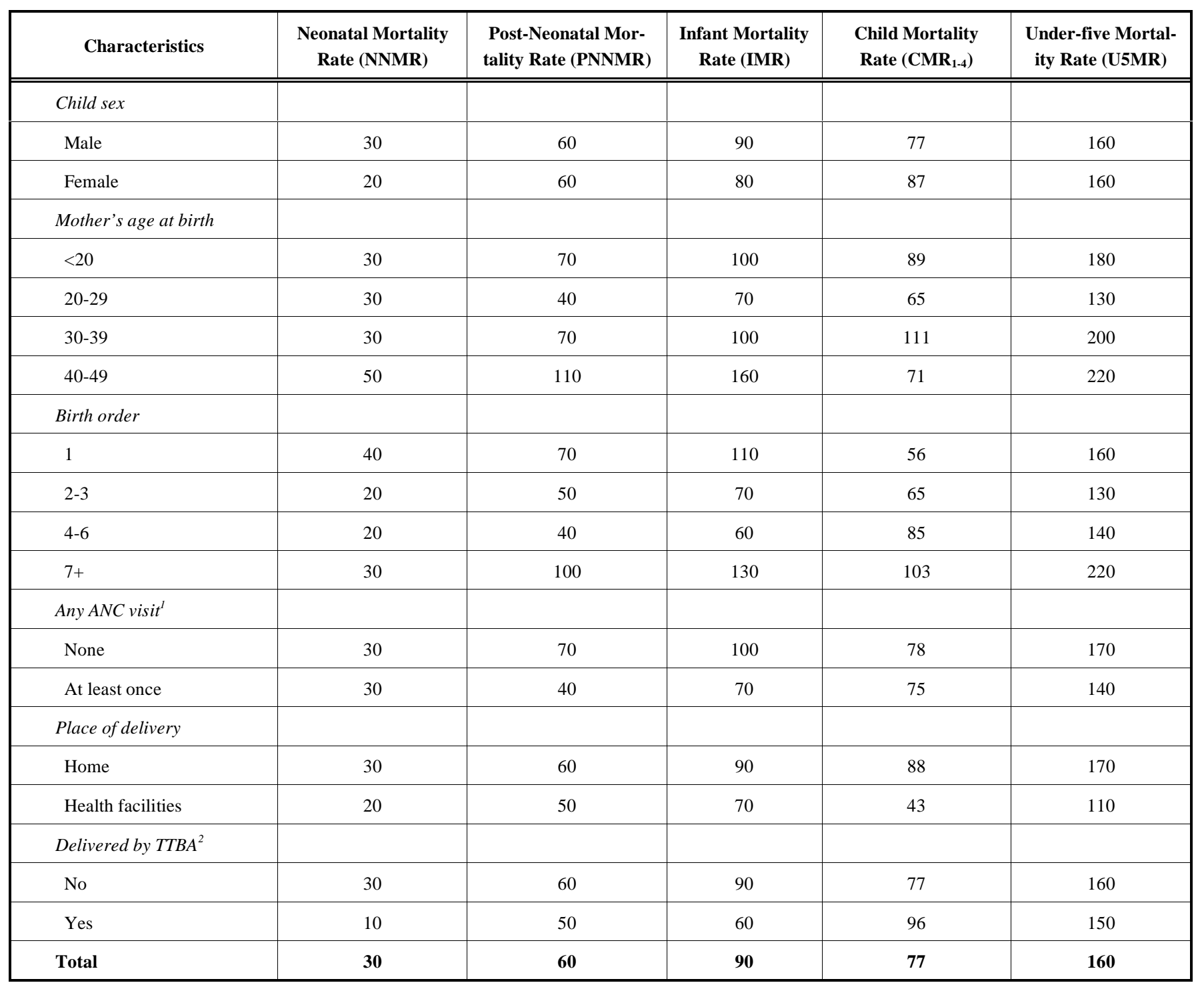

Notes: ${ }^{1}$ Antenatal care visit; ${ }^{2}$ Trained traditional birth attendant.

health-related indicators which enable us to address two key important policy issues: (1) an assessment of the extent to which women in northern Nigeria utilise health care facilities to enable them get proper maternal care, and (2) the importance of having access to skilled personnel at birth. We have observed (1) relatively high fertility rates which have been slightly declining over the recent years, (2) very low utilisation of ANC facilities, (3) lowest vaccination rates of children as compared to other countries in sub Saharan Africa, (4) poor health seeking behaviours, and (5) high infant and child mortality rates. The logistic regression of access to skilled personnel at birth on ANC attendance showed that women who attended at least one ANC visit were more likely to deliver at a health facility before and after controlling for other factors.

The results reported in this paper have a number of implications that cut across the various parts of the $\mathrm{MNCH}$ Programme. We briefly discuss selected implications that are critical to the success of the programme. The finding that women with primary or secondary schooling are more likely to deliver at a facility than women with no schooling calls for interventions that focus on women with low levels of schooling. First, the low levels of formal schooling among women imply that, where possible, attempts should be made to put all health-related information into Arabic and/or Hausa, as this will increase the number of women who can access this information. As women are likely to be learning Arabic through Quranic schools, the programme might increase partnership with local Quranic schools to include some of the basic health messages in Arabic, as it might do with the formal educational process. The other side of this recommendation is that since most women have no literacy capability, it is critical that outreach and communication strategies be adapted to pictorial, audio-visual, or participatory techniques. For example, the children's health card could be adapted with pictures to portray the number and timing of doses using the hand analogy already employed for immunisation outreach. 
The fertility rates in the programme area continue to be relatively high, but there is some evidence of an initiation of fertility decline which is apparent both for urban women and for those with higher levels of education. Because it has been documented that women under age 20 are particularly at risk for delivery complications, trends that would delay marriage and the beginning of childbearing would complement the programme's efforts to reduce maternal mortality. Similarly, trends that would reduce childbearing after age 40 , as are evidenced among urban women, would also contribute to reducing maternal mortality by reducing the number of high risk pregnancies and deliveries

Women who attended ANC delivered their most recent birth at a facility. Nevertheless, the low utilization of ANC and high proportions of women delivering at home call for more effective ways to communicate the message of risk and the feasibility of reducing this risk through skilled attendants or delivery at a health facility. Findings on low immunisation coverage underscore the importance of further strengthening the programme's initiatives to raise immunisations through increased community mobilization and outreach to build knowledge and social support for immunisations. Attention is also needed in the rural areas, to offset the educational and urban advantages in immunisation knowledge, influences, and practices.

Provision of effective MCH services can be achieved by ensuring that health facilities are staffed and able to address the PHC needs of the families they serve. These efforts may also include activities such as community education and engagement, to make sure that parents appreciate the importance of treating these illnesses promptly, even with fairly simple home-based activities.

The high mortality rates observed across the three states compared with the Nigeria DHS 2008 figures call for increased efforts in programmes that encourage women to seek ANC and delivery with a skilled birth attendant or at a health facility. This survey shows both these maternal care interventions are associated with reduced mortality rates among neonates and through infancy. The higher CMRs can be reduced by consolidating efforts across various parts of the programme and ensure that women benefit fully from different interventions.

\section{LIMITATIONS}

It is also important to note several limitations of the MNCH-BS 2009 data. In highlighting these issues, we hope to caution the reader not to overextend interpretations of findings reported herein and to take these into consideration in examining similar issues with the data.

The data come from a retrospective survey which is associated with memory-recall problems such as the detailed information collected in the pregnancy history. In addition, most of the women may have been exposed to the survey for the first time and inexperienced in comprehending and answering questions that may look simple to an average educated woman who has experienced similar surveys. The women were also tasked to answer questions that focused on difficult and painful events such as death of their children. This may lead to underreporting of such events.
High illiteracy levels in the study area may have implications on women's ability to understanding the nature of the questions which may be easily understood by literate people. For example, understanding what 'taking care of the children' implies may not be easily understood by illiterate women. The data also showed some tendency for ages to be heaped around the digit 5 and 0.

\section{CONCLUSION}

The MNCH-BS 2009 data provide an in-depth look at the $\mathrm{MCH}$ indicators in order to provide evidence-based information for launching the MNCH Programme. The key advantage of the data is that they come from a very strong sample based on all women from all the three states. The sample was structured so that we could compare, per state, areas with interventions and those without. This comparison will become useful in the future. Due to the use of the weights, the data are able to provide information for the entire area and not each state. This is very important since all the components of the programme are interlinked requiring data that cut across all components. There is a lot of information with utility in the MNCH-BS 2009 data that can be analyzed from different perspectives to aid in programme evaluation. Data on health status and health utilisation collected in the survey have both process and outcome measures. Process - e.g., did you go to ANC or clinic? And outcome: did you have a live birth, etc. The survey can both be used to establish the baseline indicators and also the uptake of the programme. By asking them in the same way at the end of the programme we will be able to have a better pre- and post-evaluation. Current efforts to establish a Health and Demographic Surveillance Site in Zamfara State will provide an opportunity to test interventions that, if proved successful, can be scaled-up to improve the lives of women and children in Nigeria and the northern zone in particular. Strategies and interventions aimed at addressing the challenges discussed in this paper should be well designed by taking into consideration the geographical and socioeconomic barriers as well as the strong cultural beliefs and practices on childbirth and fertility-related behaviors that may impede progress as we approach the MDG deadline of 2015.

\section{ENDNOTES}

1. Interestingly, there is an increasing trend among women seeking ANC from trained health professional. For example, $32.5 \%$ and $35.1 \%$ of women who gave birth in the 3 years and 1 year preceding the survey respectively ever received ANC from a trained health professional. This shows that more recent cohorts are seeking ANC from skilled professionals.

2. Although the results are not significant, $3.3 \%$ of women in Katsina knew at least six complications compared with $0.7 \%$ in Yobe and $1.2 \%$ in Zamfara.

3. The proportion of women delivering at home has been increasing among recent cohorts: $92.4 \%$ and $93.2 \%$ of women who gave birth in the 3 years and 1 year preceding the survey respectively gave birth at home.

4. Considering the high U5MR, the low NNMR may signal possible recall bias as discussed in the "Limitations" section. 


\section{ACKNOWLEDGEMENTS}

The research reported was conducted as part of the PRRINN-MNCH Programme, funded by DfID and the Norwegian Government. Special thanks go to all those who provided support during the scoping, planning and data collection: collaborators at Ahmadu Bello University (Professor Kabiru Sabitu and Dr. Tukur Dahiru); Dr. Radheshyam Bairagi; technical advisors and collaborators at Save the Children (Dr. Giorgio Cometto, Joy Lawn, Kate Kerber and Dr. Virginia Turner); the PRRINN-MNCH State Team Leaders (Drs. Ahmed Abdulwahab, Eric Amuah, Sam Bugri, and Solomon Mengiste); and the PRRINN-MNCH programme, Health Systems Research Manager, Dr. Godwin Afenyadu. Drs. James F. Phillips, Alastair Ager and Stephane Helleringer of Columbia University are acknowledged for providing technical support. The conclusions drawn and opinions expressed are those of the authors alone, and do not represent PRRINN-MNCH policy nor that of funders.

\section{REFERENCES}

[1] Babalola S, Fatusi A. Determinants of use of maternal health services in Nigeria - looking beyond individual and household factors. BMC Pregnancy Childbirth 2009; 9: 43.

[2] UNICEF. The State of the World's Children 2009. New York: United Nations Children's Fund 2008.

[3] Wall LL. Dead mothers and injured wives: the social context of maternal morbidity and mortality among the Hausa of Northern Nigeria. Stud Fam Plann 1998; 29: 341-59.

[4] Anya SE, Hydara A, Jaiteh LE. Antenatal care in The Gambia: Missed opportunity for information, education and communication. BMC Pregnancy Childbirth 2008; 8: 9.

[5] Pembe AB, Urassa DP, Carlstedt A, Lindmark G, Nyström L, Darj E. Rural Tanzanian women's awareness of danger signs of obstetric complications. BMC Pregnancy Childbirth 2009; 9:12.
[6] Myer L, Harrison A. Why do women seek antenatal care late? Perspectives from rural South Africa. J Midwifery Women's Health 2003; 43(4): 268-72.

[7] Siziya S, Muula AS, Rudatsikira E. Socio-economic factors associated with delivery assisted by traditional birth attendants in Iraq, 2000. BMC Int Health Hum Rights 2009; 9: 7.

[8] Gabrysch S, Campbell OMR. Still too far to walk: Literature review of the determinants of delivery service use. BMC Pregnancy Childbirth 2009; 9: 34 .

[9] Mubyazi GM, Bloch P, Magnussen P, et al. Women's experiences and views about costs of seeking malaria chemoprevention and other antenatal services: A qualitative study from two districts in rural Tanzania. Malar J 2010; 9: 54.

[10] World Health Organization. Pregnancy, childbirth, postpartum and newborn care: a guide for essential practice. Geneva: WHO press 2003.

[11] Darmstadt GL, Walker N, Lawn JE, Bhutta ZA, Haws RA, Cousens S. Saving newborn lives in Asia and Africa: cost and impact of phased scale-up of interventions within the continuum of care. Health Policy Plan 2008; 23(2):101-17.

[12] National Population Commission (NPC) [Nigeria] and ICF Macro. Nigeria Demographic and Health Survey 2008. Abuja, Nigeria: National Population Commission and ICF Macro 2009.

[13] National Population Commission (NPC) [Nigeria]. National Policy on Population for Sustainable Development. Abuja, Nigeria: National Population Commission 2004.

[14] Aka EO. Regional Disparities in Nigeria's Development: Lessons and Challenges for the $21^{\text {st }}$ Century. Lanham, Maryland: University Press of America 2000.

[15] Preston SH. Contribution of economic factors to declines in mortality during the twentieth century. In: Winsborough $\mathrm{HH}$, ed. Mortality in National Populations with Special Reference to Recorded Causes of Death. New York, NY: Academic Press 1972; pp. 62-88.

[16] Muhuri P, Preston SH. Effects of family composition on mortality differentials by sex among children in Matlab, Bangladesh. Popul Dev Rev 1991; 17(3): 415-34.

[17] Waldron I. Patterns and causes of excess female mortality among children in developing countries. World Health Stat Rep 1987; 40: 194-210. 